\title{
Experimental Activities in Primary School to Learn about Microbes in an Oral Health Education Context
}

\author{
Paulo Mafra ${ }^{\mathrm{a}, \mathrm{b}}$, Nelson Lima ${ }^{\mathrm{a}, \mathrm{c}}$ and Graça S. Carvalho ${ }^{\mathrm{a} *}$ \\ ${ }^{a}$ CIEC, University of Minho, Braga, Portugal; ${ }^{b}$ Polytechnic Institute of Bragança, \\ Bragança, Portugal; ${ }^{c}$ CEB, University of Minho, Braga, Portugal
}

Experimental science activities in primary school enable important cross-curricular learning. In this study, experimental activities on microbiology were carried out by 16 pupils in a Portuguese grade-4 classroom (9-10 years old) and were focused on two problem-questions related to microbiology and health: (1) do your teeth carry microbes? (2) why should you brush your teeth after meals? To solve problem-question (1), children's samples of dental plaque were prepared and observed under the microscope. For question (2), culture medium plates were inoculated with children's dental plaque either before or after tooth brushing and the colonies were counted. Results showed that pupils easily recognised the presence of microorganisms in the mouth and verified the effectiveness of the process of teeth-brushing. Pupils understood that microorganisms were potentially responsible for the onset of dental caries. These practical activities on microbiology in primary school were very effective in ensuring young children easily understand the causes of dental caries and how they can be prevented. Pupils became aware that the act of brushing their teeth is not only a socially correct behaviour or a simple rule to meet, but also a matter of preventing illness and promoting health.

Keywords: Primary school; Experimental activities; Microbes; Oral health

\section{Introduction}

Experimental science activities in primary school enable important cross-curricular learning for children at the levels of understanding, critical thinking and oral and written expression (Charpack 2005; Partridge 2006; Harlen 2007). When carried out in an atmosphere of freedom of communication and respect for others' opinions, they give rise to situations that encourage children to talk, communicate, discuss ideas, describe, interpret and challenge the results of observations; and learn and use new words to explain and sort their own ideas (Harlen 2007).

*Corresponding author. Email: graca@ie.uminho.pt 
It has been shown that the theme of microorganisms can be explored in the first years of schooling by using experimental activities (Mafra and Lima 2009; Byrne 2011; Mafra 2012). Indeed, the natural curiosity of primary school children is a gateway to effective learning about and better understanding of microorganisms (Jones and Rua 2006). In fact, some studies have shown that children are able to learn about these little beings from an early age (Byrne and Sharp 2006; Mafra and Lima 2009; Byrne 2011). However, it turns out that even after formal education on the subject, many children continue to retain alternative and contradictory ideas about the action of microorganisms that seem to endure over time. Many such ideas on microorganisms are rooted in segmented information acquired over time, are usually acquired in the family and are not based on scientific information (Byrne and Sharp 2006). Such conceptions are sometimes very resistant, making conceptual change difficult and thus constituting epistemological learning obstacles (Bachelard 1938; Carvalho et al. 2004; Carvalho and Clément 2007; Carvalho 2007).

Furthermore, understanding of the notion of 'being microscopic' is difficult, especially for young children, because it is something that cannot be seen with the naked eye. This fact points to the need to ensure children in their very early years observe live microorganisms under the microscope, and also carry out harmless experimental activities that facilitate real contact with these organisms. It was in this context that the classroom activities in our study were designed, in order to facilitate primary school pupils' learning about microbiology in basic education and contributing to a better understanding of issues related to oral hygiene. Thus, the main objectives of the practical activities consisted of making students find out they have microorganisms in the mouth and recognise the effectiveness of the process of teeth-brushing as a contribution to reducing the amount of these microorganisms, thus contributing to the promotion of oral health and prevention of dental caries.

In several countries, microorganisms are included in the science curriculum and curriculum guidelines, reflecting the importance of the topic (Byrne and Sharp 2006). In contrast, in Portugal this theme is not explicit in the primary school national programme or in textbooks; however, there is some content that addresses the issue indirectly or is associated with it (Mafra and Lima 2009; Mafra 2012).

The present work intends to join the learning of basic concepts of microbiology with health education, and more precisely oral hygiene education. The main goal was to evaluate whether the 9-10-year-old children carrying out experimental activities were able to: (1) recognise they have microorganisms in their mouth, (2) learn about simple concepts of microorganism growth, (3) verify the effectiveness of the process of teeth-brushing in decreasing the amount of microorganisms in the mouth, and so (4) understand the importance of teeth-brushing for the prevention of dental caries.

\section{Methodology}

Access to the school was carried out within the usual school rules, including a formal request for authorisation made to the Director of the Schools Group of Bragança, a town located in the North-East region of Portugal. 
The experimental activities were carried out by 16 pupils in a primary school grade- 4 classroom. Half were boys and the other half girls, and they were between 9 and 10 years old. They worked in four small groups of four pupils each.

This paper is part of a larger study on children's learning about microorganisms that included the following four microbiology topics: 'microorganisms as living beings'; 'microorganisms and food'; 'microorganisms in the environment, in industry and technology'; and 'microorganisms and health'. The research design included questioning the primary school pupils about their previous conceptions of microorganisms by administering a questionnaire containing groups of questions on the above four topics. This questionnaire was constructed and validated previously (Mafra 2012) and specific results are a matter for publication elsewhere. Data obtained from this questionnaire was used for the preparation and implementation of the activities carried out in the classroom. Being aware of children's previous conceptions (and often misconceptions), the teacher-researcher was in good position to elicit proper questioning to support children in the conceptual change to more scientific conceptions. The present work was developed under the 'microorganisms and health' topic and addressed the existence of mouth microorganisms and how to verify their existence in the mouth. With pupils' previous conceptions in mind, the teacher-researcher promoted a discussion on the topic before the classroom activities were undertaken. Children's progress in microbiology learning and oral health awareness was evaluated by class observation and pupils' written records.

The activities followed the teacher's 'pedagogical guide' proposed by Martins et al. (2008) — but adapted to suit the subject of microbiology - in four steps: (1) framing the topic microbiology into the primary school curriculum; (2) making clear the purpose of the activity; (3) discussing the activity guide with the teacher; and (4) implementing the experimental activities with the pupils.

Both experimental guides (Appendix 1 and Appendix 2) served not only as activity guides but also as recording notepads. They both had the following structure:

(1) 'Problem-question', the initial problem-question that was intended to be answered by the end of the activity;

(2) 'Before the experiment', at which point students posted their predictions;

(3) 'Experience', the sequence of the technical procedures the pupils should follow, with space for recording their observations;

(4) 'After the experience', a space for them to write down their interpretations of the results obtained and their reflections by comparing their results with their initial predictions, therefore answering the initial problem-question.

The experimental guides, designed for primary school pupils, were particularly useful in two areas: first, they served to support the implementation of activities to be carried out (both in sequence and in nature); second, they supported the pupils in making records of their observations in the form of text, drawings and tables. Thus, the experimental guide allowed the pupils to record and organize information obtained from the observed data, helping them, at the end of the guide, to answer the initial question-problem.

The experimental activities were focused on two problem-questions: 
(1) Do your teeth carry microbes?

(2) Why should you brush your teeth after meals?

Pupils discussed, drew and wrote down initial ideas about problem-question (1). After the experiment they drew and reported what they had observed and interpreted, comparing after-experiment with before-experiment. They did the same for problem-question (2).

\section{Problem-question (1): Do your teeth carry microbes?}

To solve problem-question (1), the teacher collected a sample of dental plaque from one child in each group, using a toothpick which was then placed on a microscope slide and stained with methylene blue (Figure 1). The smears were covered carefully with cover slips and were observed under the microscope at 400x and 1000x magnifications (Appendix 1).

\section{Problem-question (2): Why should you brush your teeth after meals?}

For problem-question (2) an activity was proposed in which the children observed microbial growth in Petri dishes inoculated with children's dental plaque before and after they brushed their teeth (Appendix 2). Before the classroom activity the Petri plates were prepared for microbial growth by using the culture medium nutrient agar $(5 \mathrm{~g} / \mathrm{L}$ of peptone, $5 \mathrm{~g} / \mathrm{L}$ of $\mathrm{NaCl}, 3 \mathrm{~g} / \mathrm{L}$ of yeast extract and $15 \mathrm{~g} / \mathrm{L}$ of agar as a solidifying agent).

Two Petri plates were given to each pupil group. Pupils wrote their group number and 'Before brushing' on one Petri dish cover and their group number and 'After brushing' on the other (Figure 2A). The former was inoculated (Figure 2B) with dental plaque before teeth-brushing (Plate A) and the latter with the same pupil's dental plaque after he had brushed his teeth (Plate B) (Appendix 2). Once inoculated, the plates were placed on the classroom windowsill, in the path of the sun.

Pupils were told that they would have to wait at least two days for the microorganisms to multiply. Meanwhile they were given the opportunity to verbalise their predictions. They expressed the idea that the 'before brushing' plate would house more bacterial colonies than the 'after brushing' plate, justifying this in terms of the removal of microorganisms when brushing their teeth. They associated 'brushing' and 'cleaning' with 'removing' microbes.
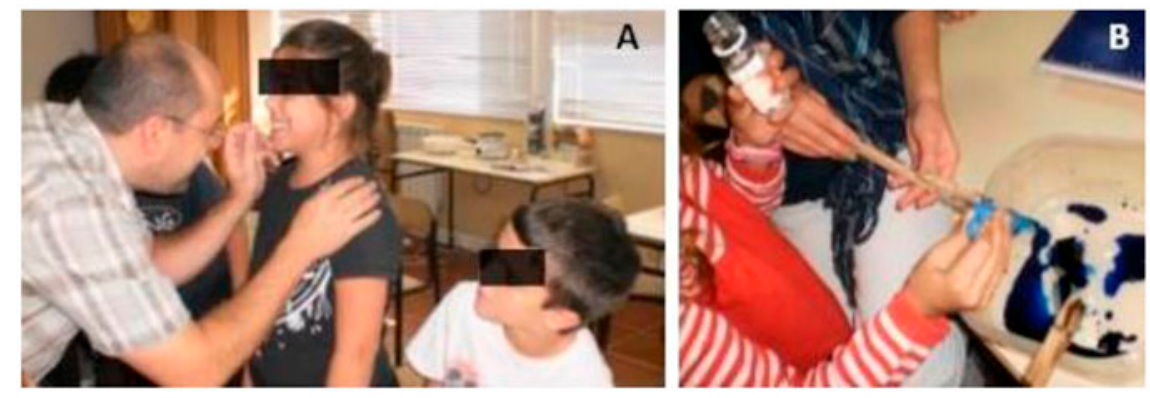

Figure 1. Collecting child's dental plaque (A) and staining it with methylene blue (B) 

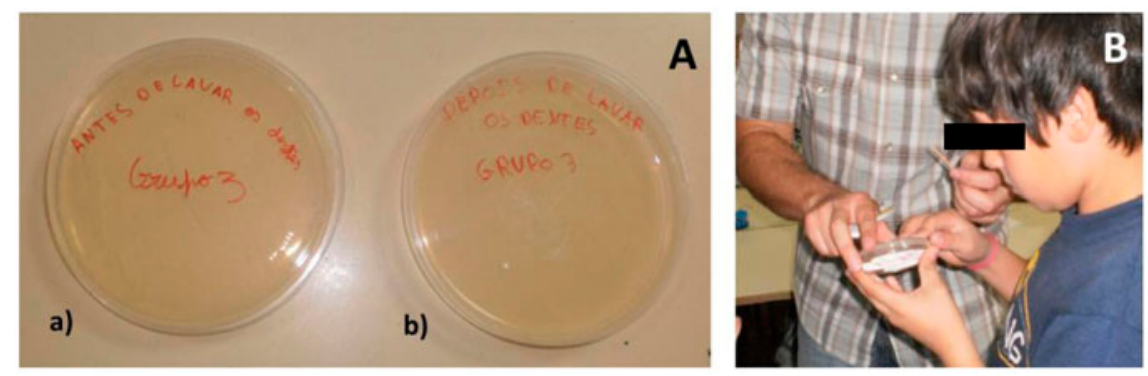

Figure 2. Petri plates (A) identified as 'Before brushing' (a) and 'After brushing' (b); and their inoculation with the child's dental plaque (B)

Two days after, pupils collected their group Petri plates A and B, observed them carefully, identified colony formation, counted the bacterial colonies on each plate and made appropriate drawings.

During the whole process, the teacher-researcher ensured children were following and understanding what they were doing and why. It was found that not only were they able to understand the concepts and processes, but they also followed the activities very enthusiastically, raising a lot of questions and trying to answer them.

\section{Findings}

The class session began with the question: have you heard of dental caries?

All pupils stated they had. However, when questioned about the cause of dental caries, there was some puzzlement and unease in the classroom. They raised the kind of food consumed, especially cakes, candies and chocolates. It was clear they did not know why dental caries occurred, but they had an idea it was linked to unhealthy food.

\section{Problem-question (1): Do your teeth carry microbes?}

The second question concerned the nature of dental plaque. Most pupils identified it as a substance consisting of food scraps that get attached to the teeth. When the possibility of the existence of microbes in dental plaque was addressed, there was some resistance to this idea and, in particular, some students expressed disbelief.

Most pupils felt having microbes in the mouth was not at all natural. However, there were two children who agreed with the possibility of microbes existing on the teeth. They were asked how they could find out whether or not there are microbes in dental plaque. They readily suggested use of the microscope as a tool to see microbes, which suggested they understood the purpose of this instrument.

The experimental guide (Appendix 1) was then given to the pupils. In the first part of the guide, 'Before the experiment', they were asked to 'Record in the box below what you think you would see in a piece of dental plaque observed under the microscope'. These are some of their responses:

- A white paste that smells bad (G4 pupil);

- I think we would observe a white dash with very tiny white dots (G1 pupil); 
- I would watch some microbes of the dental plaque (G4 pupil);

- I think I would see microbes gnawing the tooth plaque (G2 pupil);

- I think my teeth have microbes and the dental plaque would have the microbes (G3 pupil).

After registering their predictions, pupils carried out the activity, following the instructions in the experimental guide (Appendix 1), as described in the Methodology section. They watched with curiosity the preparation of the microscope (Figure 3A). When they became able to identify the microorganisms (blue dashes), they became excited and wanted to be sure they were seeing real microorganisms. Having had their suspicions confirmed, they commented to each other, with disbelief on their faces, that they had microbes on their teeth!

Since all pupils were able to see the bacteria under the microscope, the teacher gave a short explanation of two forms of bacteria, coccus (spheres) and bacillus (rods), in order to make them aware of both concepts and able to identify cocci and baccilli under the microscope.

After these observations and identification of microorganisms, pupils drew on their experimental guide (Appendix 1), in the item 'Experiment', section 'We observed that...' (see Appendix 1). These are some examples of what they mentioned:

- We found that dental plaque consists of bacteria and food debris (G1 pupil);

- We found that the teeth have bacteria and food debris, and the bacteria are in the form of a wire and of a ball. The balls are called cocci and wires are called bacilli (G4 pupil);

- In the dental plaque there are bacteria that are cocci and bacillus (G2 pupil).

The responses showed that pupils came to recognise the presence of bacteria in dental plaque. Furthermore, they began acquiring vocabulary related to the topic, as they associated the terms 'cocci' or 'bacilli' with different forms of bacteria.

Problem-question (2): Why should you brush your teeth after meals?

Following the previous activity, the answer to problem-question (2) was easy for children: 'at the end of the meals we get food debris on teeth; germs will build up and
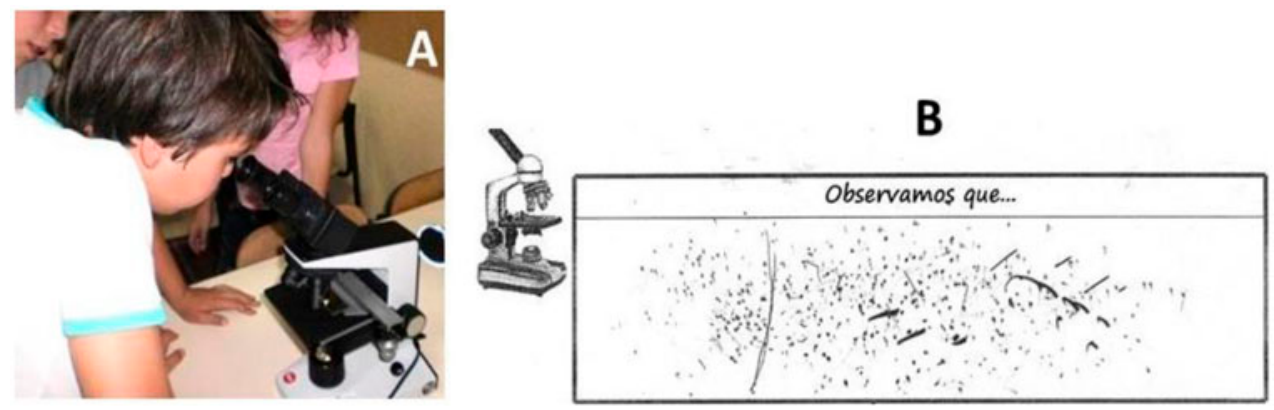

Figure 3. Pupil observing a dental plaque smear (A) and the respective drawing (B) 
can cause tooth caries' (G4 pupil) and 'tooth-brushing reduces microorganisms in the mouth' (G3 pupil). To test this hypothesis, culture medium in Petri plates were inoculated with children's dental plaque either before or after tooth brushing (see Methodology and Appendix 2). Each group selected one child to provide dental plaque before and after he/ she brushed his/her teeth. Pupils were easily able to verify the reduction of microorganisms after tooth brushing (Figure 4A and Figure 5) and record the results in the respective box in the activity guide (Figures $4 \mathrm{~B}$ and Figure 6).

Figure 5 shows Group 4's Petri plates with bacterial colonies obtained from the dental plaque before teeth-brushing (Plate A) and after (Plate B).

Figure 6 shows drawings by a Group 2 pupil about the results of bacterial growth on Petri plates before (Plate A) and after (Plate B) teeth-brushing.

On the record sheet of the activity guide, pupils made the following statements:

- Before [teeth-brushing] the plate had bacteria and after [tooth brushing] had no more (G4 pupil);

- Before brushing, the teeth had many bacteria and after brushing the teeth had few (G3 pupil);

- The plate before tooth brushing has more bacteria than the plate after tooth brushing (G2 and G4 pupils).

After inside-group analysis, pupils compared their group plates (A and B) with the equivalents of the other groups and were easily able to identify differences in the number of bacteria between plates $\mathrm{A}$ and $\mathrm{B}$, confirming their predictions. The pupils were then ready to complete their activity guide (Appendix 2) by recording their answer to the initial problem-question: 'Why should you brush your teeth after meals?'.

Representative answers include:

- To have no bacteria on the teeth (G1 pupil);

- Yes, because then you can have a lot of bacteria on the teeth and this is very bad (G3 pupil);

- Because if we do not brush the teeth we can get caries (G1 pupil);

- We brush after meals because otherwise we can catch diseases like caries (G4 pupil);

- Because we keep bacteria and develop caries and so teeth get holes (G4 pupil).
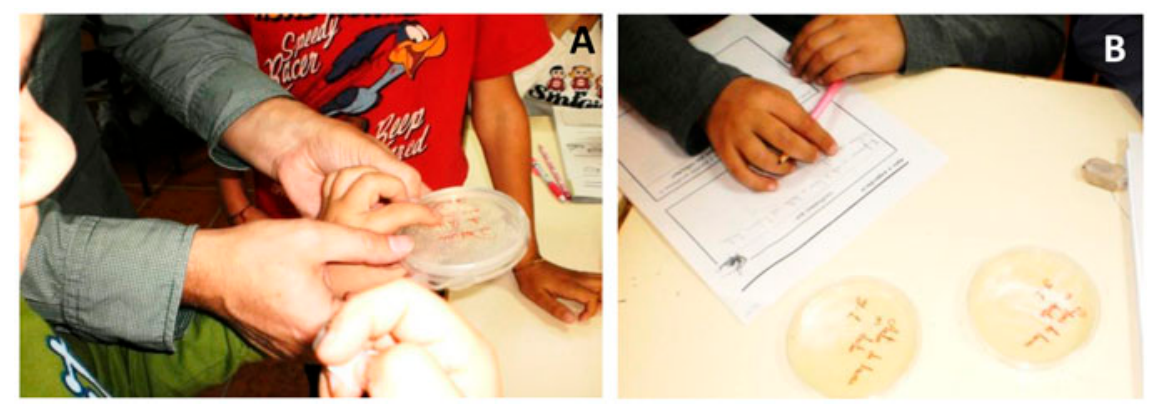

Figure 4. Observation of the contaminated Petri plates (A) and recording the microbes' colonies (B) 


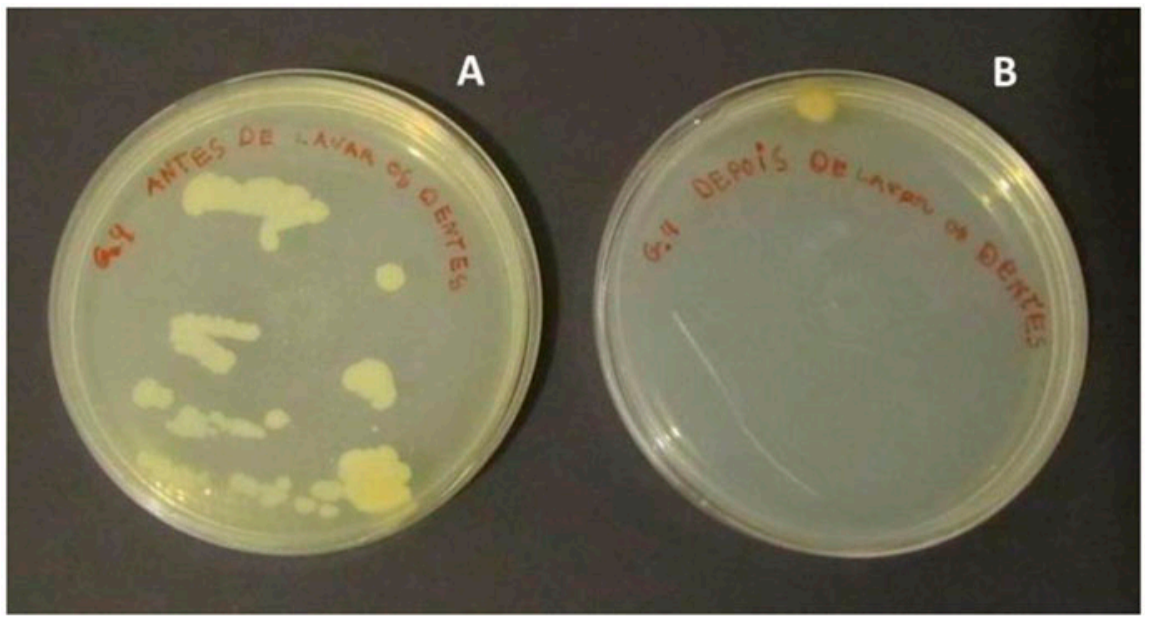

Figure 5. Bacterial colonies grown in Group 4 Petri plates 'Before teeth-brushing' (A) and 'After teeth-brushing' (B)

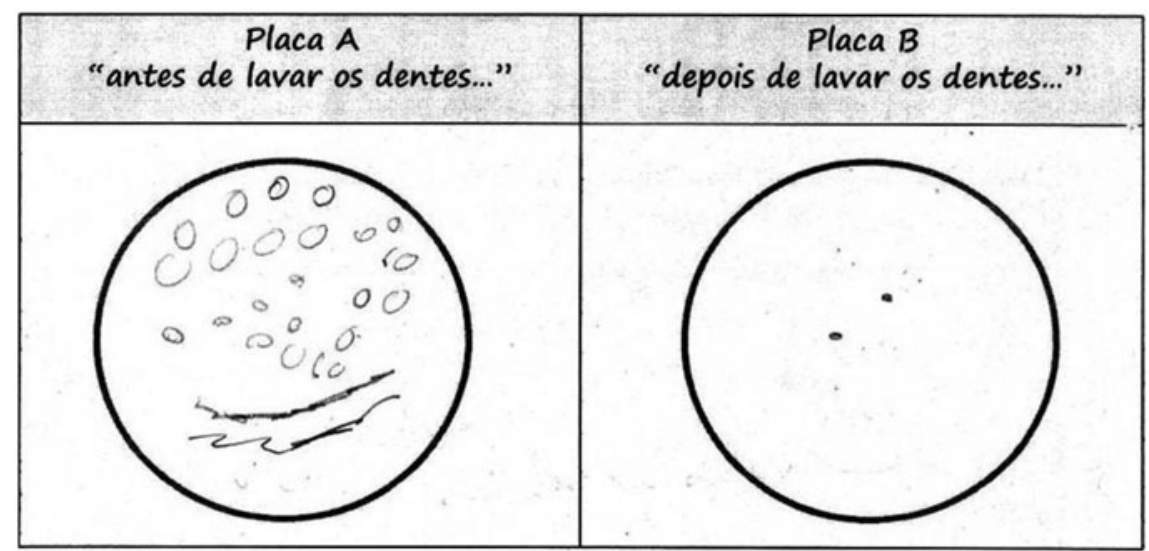

Figure 6. Records of a Group 2 pupil on observation of his group Petri plates inoculated with dental plaque of a child either before ('Placa $A$ ') or after ('Placa $B$ ') teeth-brushing

\section{Conclusions and Educational Implications}

A first aspect to address with regard to the pupils' cognitive level is that both experiments (microscopic observation of bacteria and macroscopic observation of bacterial colonies) allowed them to understand two visualisation levels: first, isolated individual bacteria are only visible with the aid of a microscope; second, bacterial colonies (arising from the proliferation/replication of bacteria in culture medium) are easily identifiable to the naked eye.

A second important aspect to consider relates to the implementation of these experimental activities, which contributed to improvement in pupils' perceptions concerning recognition of the presence of microorganisms in the mouth. Individual pupils' records, 
containing their drawings and writings, were shown to be an important tool in monitoring their learning from experimental activities. Also, behaviours related to personal hygiene, including teeth-brushing, came to be understood as behaviours related to the elimination of microbes that are potentially harmful to health.

This was a successful teaching and learning activity but it has some limitations with regard to large-scale application in primary schools, since it requires some equipment and materials to be prepared backstage. Collaborations between schools and universities (or other higher education institutions) are a good way to provide interesting experimental activities in primary schools.

In brief, through these practical activities, pupils learned: (1) about the presence of microorganisms in the mouth, (2) that microorganisms grow in an adequate culture medium (3) and that teeth-brushing decreases the amount of microorganisms on the teeth; in this way (4) pupils could easily understand the importance of teeth-brushing for the prevention of dental caries. With these simple microbiological activities children came to understand that oral hygiene is a matter of preventing illness rather than just a socially correct behaviour or a simple rule to meet.

However, it is possible that children have retained the idea that brushing their teeth is enough to remove all bacteria in their mouth or that the simple fact that bacteria are in the mouth is enough to give rise to dental caries. Indeed, opportunistic infections and other complex issues should be a subject of teaching and learning at higher school levels.

The type of activity guide used in this work allowed the children to undertake all activities in a climate of reflection and to answer the initial problem-questions with ease. In this regard, it was found to be important for learning to include practical activities involving children in research processes that were accessible for them. Another aspect that was revealed to be of paramount importance was the teacher's awareness of children's previous conceptions, so that he could ensure the progress of children's learning about the structure, functions and applications of microorganisms.

Such experimental studies on microorganisms should be progressively developed over primary and secondary school teaching; indeed, this occurs in many countries (Byrne and Sharp 2006; Byrne 2011; Mafra 2012). However, in the Portuguese primary school (the first four years of compulsory school, with children between 6 and 10 years old), explicit reference to microorganisms is absent (Mafra and Lima 2009), which means that as far as the process of didactic transposition is concerned, there is a need to rethink this problem in terms of not only the curriculum but also textbooks (Clément 2004; Tracana et al. 2008; Carvalho et al. 2009). Didactic transposition concerns the transferring of knowledge from the real world into the world of education. This process implies two levels of analysis: first, when and how national programmes or syllabuses approach the issue (external didactical transposition-EDT); second, how school textbooks address the issue of pupils' learning (internal didactical transposition-IDT) (Carvalho et al. 2009). Therefore attention should be given not only to the school level for introducing microorganisms in the programmes (EDT) but also to how the microbiology topic is addressed in textbooks (IDT). The present study showed that young children are able to learn about elementary microbiology, indicating that this topic can be introduced in primary school programmes (EDT), but particular attention must be paid to how it is addressed in textbooks to ensure that children can understand it (IDT). 


\section{Funding}

This work had financial support from CIEC (R\&D Unit 317 of FCT, Fundação para a Ciência e Tecnologia) [PEst-OE/CED/UI0317/2011].

\section{References}

Bachelard, G. 1938. La Formation De L'Esprit Scientifique [The Formation of the Scientific Mind]. Paris: Vrin.

Byrne, J. 2011. "Models of Micro-Organisms: Children's Knowledge and Understanding of Micro-Organisms from 7 to 14 Years Old." International Journal of Science Education 33 (14): $1927-1961$.

Byrne, J., and J. Sharp. 2006. "Children's Ideas about Micro-Organisms." School Science Review 88 (322): 71-79.

Carvalho, G. S., and P. Clément. 2007. "Relationships between Digestive, Circulatory and Uniary System in Portuguese Primary Textbooks." Science Education International 18 (1): 15-24.

Carvalho, G. S., D. Jourdan, A. Gonçalves, C. Dantas and D. Berger. 2009. "Addictive Substances: Textbook Approaches from 16 Countries." Journal of Biological Education 44 (1): 26-30.

Carvalho, G. S., R. Silva, N. Lima, E. Coquet and P. Clément. 2004. "Portuguese Primary School Children's Conceptions about Digestion: Identification of Learning Obstacles." International Journal of Science Education 26 (9): 1111-1130.

Carvalho, G. S., R. Silva, and P. Clément. 2007. "Historical Analysis of Portuguese Primary School Textbooks (1920-2005) on the Topic of Digestion." International Journal of Science Education 29 (2): 173-193.

Charpack, G. 2005. As Ciências Na Escola Primária: Uma Proposta De Acção [Science in Primary School: A Proposal for Action]. Mem Martins. Editorial Inquérito.

Clément, P. 2004. "Science Et idéologie : Exemples En Didactique Et épistémologie De La Biologie." [Science and Ideology: Examples in Biology Education and Epistemology] In Colloque Science Médias - Société, 53-69. Berne: Joelle Le Marec.

Harlen, W. 2007. Enseñanza y Aprendizaje de las Ciencias [Teaching and Learning Science]. Madrid: Ediciones Morata.

Jones, M. G., and M. J. Rua. 2006. "Conceptions of Germs: Expert to Novice Understandings of Microorganisms." Electronic Journal of Science Education 10 (3): 1-40.

Mafra, P., and N. Lima 2009. "The Microorganisms in the Portuguese National Curriculum and Primary School Textbooks. Current Research Topics in Applied Microbiology and Microbial Biotechnology." Proceedings of the International Conference on Environmental, Industrial and Applied Microbiology (BioMicroWorld 2007), Seville, Spain, Hackensack: World Scientific.

Mafra, P. 2012. "Os Microrganismos No 1. ${ }^{\circ}$ E 2. ${ }^{\circ}$ Ciclos Do Ensino Básico: Abordagem Curricular." Conceções Alternativas E Propostas De Atividades Experimentais, Institute of Education. Braga, University of Minho. PhD.

Martins, I. P., M. L. Veiga, F. Teixeira, C. Tenreiro-Vieira, R. M. Vieira, A. V. Rodrigues, and F. Couceiro. 2008. Mudanças De Estado Físico - Guião Didático Para Professores. Lisboa: Ministério da Educação.

Partridge, J. 2006. "Conducting a Science Investigation in a Primary Classroom." Teaching Science 52 (2): 44-45.

Tracana, R. B., C. Ferreira, M. E. Ferreira, and G. S. Carvalho. 2008. "Analysing the Theme of Pollution in Portuguese Geography and Biology Textbooks." International Research in Geographical and Environmental Education 17 (3): 199-211. 
Appendix 1

Problem-Question I:

Do your teeth have microbes?

\section{Before the experiment}

1 - Check if you have all the equipment necessary to carry out the experiment:

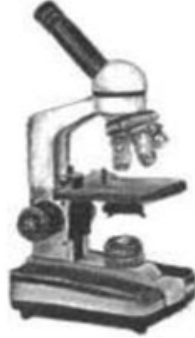

Methylene blue

Microscope

Petri dishes with culture medium

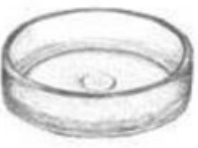

Wash squeeze bottle
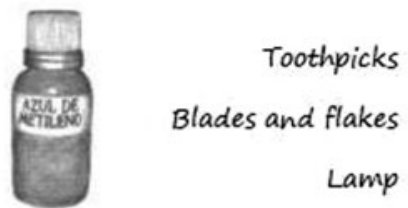

Wooden tweezers

Tooth brush

Toothpaste

Immersion oil
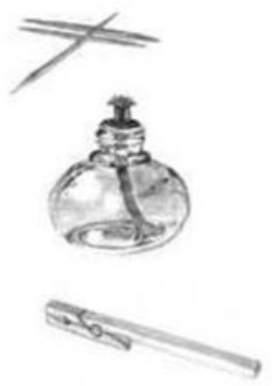

2 - In the box below record what you think that you would observe in a piece of dental plaque on the microscope.

I think I would observe... 


\section{Experiment}

\section{3 - Execute the plan:}

a) With the dropper, put a drop of water on a glass slide.

b) Pass a toothpick between the teeth and gums (very carefully so you do not hurt yourself).

c) Touch with the toothpick on the drop of water so that the sample pass to the drop and slightly spreading the mixture on a microscope slide.

d) Ask the teacher to help bring the blade flame and color it with methylene blue.

e) Observe under the microscope, with the teacher help, and record your observations.

\section{We observed ...}

\section{After the experiment}

We found that ...

After discussion, write the answer to the problem question: Do your teeth have microbes? 
Appendix 2

Problem- question II:

\section{Why should you brush your teeth after meals?}

\section{Experiment}

Let's check your mouth BEFORE and AFTER brushing your teeth!

a) Before you brush your teeth, passe a toothpick between the teeth and inoculate the Plate A.

b) Brush your teeth using a toothbrush and toothpaste.

c) Came back and use another toothpick. Pass it between the teeth and inoculate the plate $B$.

d) Put the two plates in a warm place (near the window) and wait two days.

e) Draws the results in the following table.

\begin{tabular}{|c|c|}
\hline $\begin{array}{c}\text { Plate A } \\
\text { "Before brushing teeth ..." }\end{array}$ & "After brushing your teeth ..." \\
\hline & \\
\hline
\end{tabular}




\section{After the experiment}

We found that ...

After discussion, write the answer to the question-problem:

Why should you brush your teeth after meals? 